\title{
Green Infrastructure Emergency: Abandoned Development
}

\author{
Nurul Fitria Marina \\ \{nufina.ku@gmail.com\} \\ Universitas Muhammadiyah Surabaya, Sutorejo Street no.59 Surabaya
}

\begin{abstract}
Development, both on a large scale and small scale, must have a connection with environmental development. However, in the development of the environment, especially the green environment, it is often abandoned and not well planned. This can be seen in the length of post-development environmental recovery. Impression of hot, dirty, dry, and not beautiful to be a scene that must be faced for several years after development. Green Open Space that is presented is generally only a tree that is not arranged through design and aesthetics. Of course this is very unfortunate considering the condition of the natural environment is inversely proportional to urban development. So, there needs to be more attention for planners, designers, and construction practitioners in paying attention to this matter.
\end{abstract}

Keywords: green infrastructure, built environment, sustainable Development

\section{Introduction}

Sustainable development is a development that consider the balance between economy, social welfare and environment along with the implementation of renewable energy. Sustainable development is a development that unites every infrastructure and is interrelated. However, what is seen now is physical development in the form of transportation lines and technology and their buildings. Especially the green infrastructure which is currently very scarce. The lack of infrastructure needs to be a subject when planning and construction. Seeing the development of the city that is currently rife, criticism of the negative effects on the environment is rarely heard. The rise of physical development certainly reduces green land, especially if no green land replacement is prepared. The impact of the lack of green land is the lack of clean air, the lack of water catchment areas so that flooding is widespread. Green land functions, among others: bio-ecological functions, socio-economic economic functions, aesthetic functions.

Development and technological progress have risks to decrease the extent and quality of the environment. Infrastructure development is not only in the form of roads and buildings, but also drainage, green space, and utilities. Technology as part of the utility and as a medium to facilitate performance actually forgets the relationship between the environment and technological progress.

Development and technological progress certainly hope for a better life for humans, but humans also need a good environment so that humans are physically and psychologically controlled. By looking at the phenomena that occur, especially in Indonesia, it will be seen 
problems, conditions on the ground, and solutions to the challenges of development and technological progress.

The aim of this study was to find out the environmental solutions in carrying out development and technological development, and a reminder of the manifestation of sustainable development.

\section{Methodology}

The method used was phenomenological qualitative which saw a current experienced event visibly. The stages need to be performed were the focus of research, data, data analysis, results, and recommendations.

Phenomenological method : (1) Focus of the Problem, problems raised was in the form of events or things that occur around us both in the form of social studies and the natural environment. (2) Data Information, the data obtained was based on observations, interviews, and documentation. Data was not nominal, but based on objective findings in narratives. (3) Analysis, presentation of the analysis was analytical descriptive by multiplying data information, connecting with various sources, comparing, and finding the results. (4) Results, presentation of the results of the analysis has answered the questions of the raised issues. (5) Recommendations, recommendations were made so that events or problems that occur could be minimized and avoided.

\section{Result and Discussion}

\subsection{Focus of the Problem}

The concept of a sustainable city cannot be optimally performed, provided that the focus of attention on the physical development of the city and transportation. The phenomenon seen around us today was the absence of an aesthetic planning about the presence of green space as part of sustainable development. The development and technology that were formed actually leave the environment as a counterweight to development. In building design, almost no attention was paid to landscape design or other green open space.

Architecture as a science in design has a lot of focus on buildings. In fact, environmental design, in this case green space, was part of the aesthetic value of a building object. For example, development in major cities in Indonesia.

\subsection{Data Information}

Sustainable development certainly created a sustainable city, where sustainable cities were the cities that enable citizens to meet their needs and improve their welfare without reducing current or future environmental conditions.

The principles of a sustainable city:

a. Environmental carrying capacity, the city is designed and managed within the limits determined by the natural environment and its carrying capacity

b. Reversibility, reversible intervention so that cities can adjust the challenges without disturbing the environmental carrying capacity.

c. Resilience, cities are flexible and able to respond to external pressures.

d. Efficiency, the economic benefits of environmental efficiency.

e. Justice / equity, resources and services are able to reach all city residents. 
The concept of sustainable cities were promoting ecologically designed buildings, reducing the volume of vehicles with alternative modes, promoting recycling programs, providing wider green space, maintaining natural habitats.

The rise of vertical housing construction was inversely proportional to the environmental conditions in the site. This was very visible in parking areas and parks. The parking area was focused on parking arrangement and vehicle circulation, but the shade and beauty of the parking area was often overlooked. For stakeholders, the park area was often considered an empty land that can make money, so it often closed the park by making it a building.

Based on interviews with users of newly built objects, feel that the impression of aridity and heat cannot be separated in development. In addition, it was very apparent that there was no unity of planning between buildings and the environment, especially green land. There needed to be further emphasis on the importance of unity of planning and design of buildings with their environment.

In addition to building, infrastructure development that was very visible was road construction. The construction of the cross-provincial road seems to be a major work and was needed by the community to improve the economy. The road construction must have previously been in the form of green or forested land. In the process, the impression of dirty and arid did not escape the sight.

\subsection{Data Analysis}

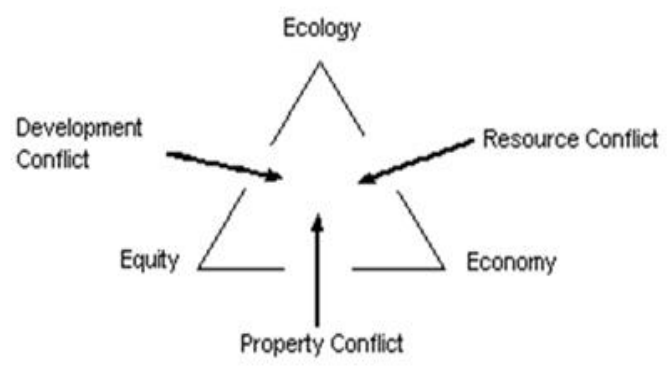

Fig. 1. Primary Principles of Sustainable Development

Based on the scheme in the figure showed the relationship between economic, development, and environment that could not be separated and go hand in hand. But what was seen now, development was focused on a small part of the element of sustainable development.

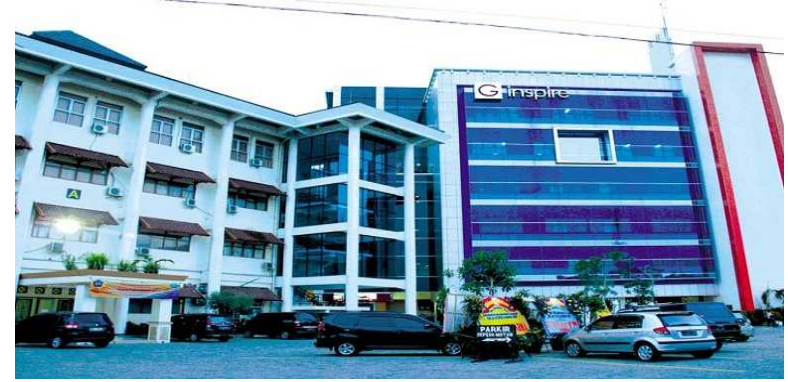

Fig. 2. Building And Parking Area With Lack Environment 
Based on the picture, it appeared that parking as part of the design, was actually designed "just" and what it was. Supported by the procurement of trees without careful design. The trees that were actually provided will grow as expected after the next few years. However, there was still a need for design so as not to impress the "rest" of development and be the last concern.

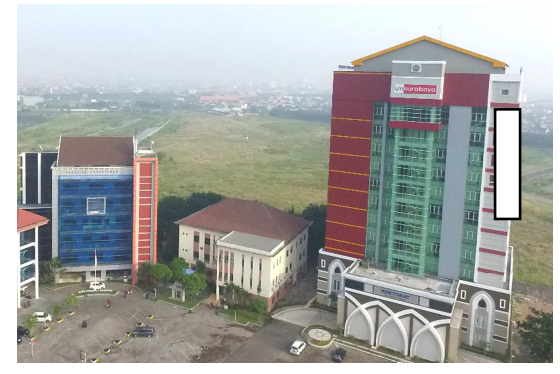

Fig. 3. Building And Parking Area With Lack Environment

In Figure 3, it was the same location but in a different year from Figure 2. In Figure 2, it was a picture before construction of a new building, but in Figure 1 there appeared to be no change in the environment when the construction was complete.

This showed that there was no difference in the conditions of improvement between before and after development. In addition it also showed the environmental conditions that were increasingly neglected and were not a counterweight to development.

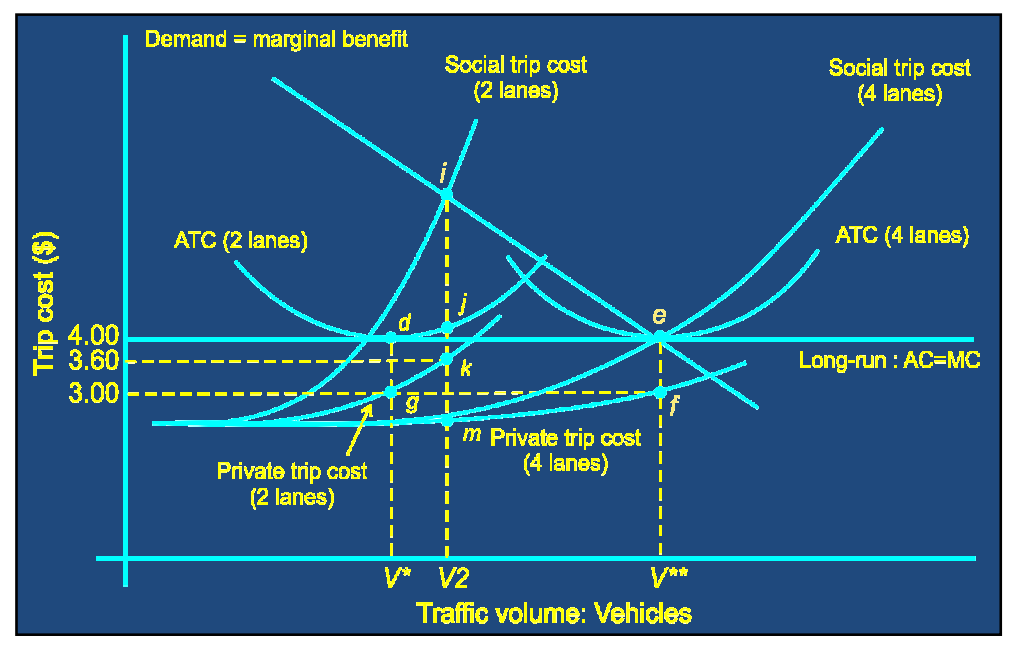

Fig. 4. Expand Capacity of Roads

Road construction as a form of ease of access, turned out to be inversely proportional to the concept of sustainable development, which needed to reduce the number of vehicles. Road construction and the addition of road segments were also expected to be a solution to traffic congestion, but if you see Figure 4, it was clear that the construction and addition of roads actually increase traffic jams. 


\subsection{Results}

Based on the results of the analysis of some of these findings, showed that the development carried out was inversely proportional to the announced planning and concept of sustainable development. Almost all aspects of development that were currently still running were not in accordance with the concept of sustainable development. Green Open Space as part of green infrastructure was always ignored and the final result in development, no longer part of development such as the concept of sustainable development.

\subsection{Recommendations}

There is a need for concrete and real action on sustainable development so that people can enjoy the results even into the future. Green space or green infrastructure needs to be part of the design.

\section{Conclusions}

Green infrastructure continues to be a discussion of environmentalists. Development will be balanced and sustainable if the construction designers and actors continue to pay attention to green land in the process.

\section{Suggestions}

Educators need to implant and train learners to include green land in every dsign. For construction players, there needs to be awareness and concrete action on the importance of green land in a development. For capital owners (business people), profits are not only gained from physical sales but also the provision of the environment to be of added value and increase the sale value of a place. For the government, people's welfare is assessed from the quality of their lives so that they are able to work optimally and improve the economy.

\section{References}

[1] Holden, E.: Ecological Footprints and Sustainable Urban Form, Journal of Housing and the Built Environment. pp. 19 (2004)

[2] Jabareen, Y.R.: Sustainable Urban Forms. Their Typologies, Models, and Concepts, Journal of Planning Education and Research. pp. 26 (2006)

[3] O'Sullivan, A.: Urban Economics 9th Edition. McGraw Hill. (2009)

[4] Wheeler, S.M.: Planning for Sustainability: Creating Livable, Equitable, and Ecological Communities. Routledge, London (2004)

[5] EEA. European Environment Agency (1995) 